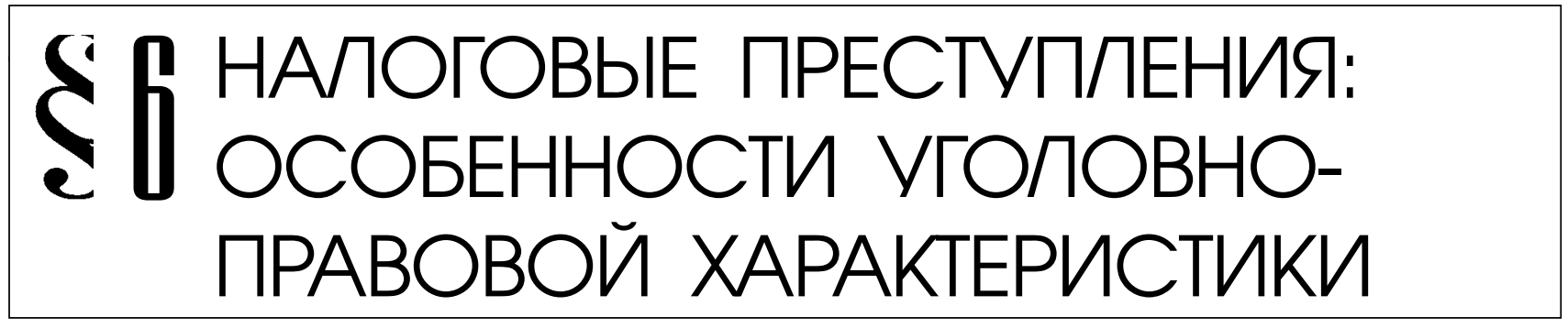

А.Э. Салказанов

\title{
АКТУАЛЬНЫЕ ВОПРОСЫ СОВЕРШЕНСТВОВАНИЯ УГОЛОВНОЙ ОТВЕТСТВЕННОСТИ ЗА УКЛОНЕНИЕ ОТ УПЛАТЫ НАЛОГОВ И (ИЛИ) СБОРОВ С ОРГАНИЗАЦИИ В РФ (СТ.199 УК РФ)
}

Аннотация: Данная статья посвящена уголовно-правовой норме об ответственности за уклонение от уплаты налогов и (или) сборов в Российской Федерации. Автором поднимаются вопросы законодательной регламентации и совершенствования нормы статьи 199 Уголовного кодекса РФ. Приводится правоприменительная практика об ответственности за данное преступление, обосновываются необходимость нового подхода законодателя к разрешению вопросов о налоговой преступности. В частности, автор указывает на способы совершения налогового преступления, момент его окончания, несовершенство описания примечания состава преступления предусмотренного сm. 199 Уголовного кодекса РФ, а также вопросы несовершенства взаимодействия налогового и уголовного законодательства. Основными используемыми методами выступили: материально-диалектический метод, методы анализа и синтеза, исторический, логический и системный методы, а так же формально-юридический метод познания. Изменения в налоговом законодательстве, возникающие вопросы теории и правоприменения состава статьи 199 Уголовного кодекса РФ, способствует необходимости нового подхода к данной норме. Автором делаются выводы о необходимости включении в диспозицию данной нормы признака "иной способ», изменение признака «совершенное в крупном или особо крупном размере», а также реконструкция признаков, указанных в примечании этой статьи.

Ключевые слова: уголовная ответственность, налоговые преступления, организации, объективная сторона, способы совершения, крупный размер, налоговое законодательство, состав преступления, налоговое преступление, уклонение.

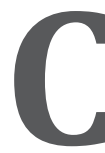

развитием рыночной экономики, финансовых механизмов государственного регулирования в России, актуальностью решения вопросов, связанных с мировым финансовым кризисом, всё больший интерес общественности представляет государственное регулирование, а так же охрана механизмов обеспечения финансовой стабильности государства. Одним из соответствующих гарантов здесь выступают нормы об уголовной ответственности за налоговые преступления. Данную разновидность преступности относят к разряду преступности в сфере экономической деятельности или же «беловоротничковой преступности».

Уголовный Кодекс РФ (далее по тексту УК РФ) предусматривает различные нор- 
мы об ответственности за данные преступления. Остановимся на изучении одной из них. Объектом нашего исследования выступает норма об уголовной ответственности за уклонение от уплаты налогов и (или) сборов с организации в РФ (ст. 199 УК РФ).

С момента принятия УК РФ 1996 года, диспозиция состава ст. 199 УК РФ дважды подвергалась изменениям (в ред. от 25 июня 1998 № 92-ФЗ и в ред. от 08 декабря 2003 № 162-Ф3). Эволюционирование нормы о данном налоговом преступлении, в то же время не говорит о том, что в данном вопросе поставлена окончательная точка. Возникающие вопросы правопонимания и применения состава статьи 199 УК РФ способствуют дальнейшей разработке и совершенствованию этой нормы. В связи со сказанным, для достижения единого научного и практического подхода попробуем разобраться в некоторых неоднозначных вопросах состава преступления, предусмотренного ст. 199 УК РФ.

С точки зрения единообразия объективной стороны, пожалуй, одним из дискуссионных вопросов остается способ совершения данного преступления. Известно, что здесь предусматривается пассивный непредставление налоговой декларации или иных документов, и активный способ совершения преступления - включение в налоговую декларацию или иные документы заведомо ложных сведений. Оба вышеупомянутых способа подпадают под категорию «уклонение», под которым понимается стремление избежать уплаты налогов полностью или частично. Так пункт 3 постановления Пленума Верховного суда РФ от 28 декабря 2006 г. № 64 «0 практике применения судами уголовного законодательства об ответственности за налоговые преступления» трактует уклонение как - умышленное деяние, направленное на неуплату налогов и (или) сборов.

В связи с казуистичным описанием способов совершения налогового преступления в норме ст. 199 УК РФ, в научной литературе возникла широкая дискуссия по вопросу рациональности такой оговорки. Так А.П. Кузнецов отмечал, что не следует «привязывать» уклонение от уплаты налогов к конкретному способу ${ }^{1}$. С.В. Сорокин также говорил о сужении объективной стороны законодательным описанием способов совершения налогового преступления ${ }^{2}$. Обратной позиции придерживается И.И. Кучеров, отмечающий то, что указание на способ совершения в диспозиции нормы не говорит о сужении его характера, а лишь описывает некоторые возможные способы «уклонения», тогда как указанный термин следует трактовать широко и под него подпадают и иные способы уклонения от уплаты налогов ${ }^{3}$.

Следует согласиться с авторами, указывающими на недопустимость законодательного сужения способов уклонения от уплаты налогов. Обратное же положение, на практике не отражает в полной мере принципы применения уголовного закона, в частности, недопустимость расширительного толкования норм о преступности и наказуемости деяния.

Обратимся к судебной практике: так руководитель 000 «Дельта» 0. закупал

\footnotetext{
1 См.: Кузнецов А.П. Политика государства в налоговой сфере: уголовно-правовые средства и организационнотактические методы. Н. Новгород., 1995. С. 199-201.

2 См.: Сорокин С.В. Уклонение от уплаты налогов по проекту Уголовного кодекса // Вопросы уголовной ответственности и её дифференциации (в проекте особенной части Уголовного кодекса): сборник научных статей и тезисов. М., 2000. С. 192-193.

3 См.: Кучеров И.И. Налоговая преступность: криминологические и уголовно-правовые проблемы. дисс... докт. юрид. наук. М., 1999. С. 275.
} 
за наличный расчёт сантехническое оборудование, которое поставлял на предприятия Челябинской области. В зачёт поставленного оборудования О. получал продукцию указанных предприятий и реализовывал её через розничную торговлю. При этом, осуществляя хозяйственные операции и используя реквизиты 000 «Дельта», О. не ставил в известность бухгалтера предприятия и отчетность в налоговые органы не представлял. В результате этих действий в бюджет не были уплачены налоги в крупном размере. Приговором Озёрского городского суда 0 . осужден по ч. 1 ст. 199 УК РФ 4 .

Представляется, что данный пример не в полной мере отражается в диспозиции ст. 199 УК РФ, и более правильной является позиция ученых, относящих данные случаи к «иным способам» совершения налогового преступления. Вместе с тем мы считаем не правильной позицию законодателя, который ФЗ от 8 декабря 2003 г. № 162-Ф3 исключил указание на «иной способ» совершения этого преступления, ссылаясь на неправильное применение данной нормы правоохранительными органами, когда преступным стали квалифицировать и простой факт неуплаты налогов. Не смотря на то, что ещё ранее в постановлении Конституционного Суда РФ от 27 мая 2003 г. № 9-П «По делу о проверки конституционности статьи 199 УК РФ...», подчеркивалось то, что составообразующим здесь может признаваться только такое деяние, которое совершается с умыслом и направлено на избежание уплаты налога в нарушение установленных налоговым законодательством правил.

\footnotetext{
4 Цит. по: Соловьёв О.Г. Техника законодательной регламентации уголовной ответственности за уклонение от уплаты налогов и таможенных платежей: Монография. М.: Юрлитинформ, 2010. С. 127.
}

Как справедливо указывает И.А. Клепицкий, анализ распространенных в современной России схем «оптимизации налогообложения» показывает, что почти все эти схемы являются криминальными ${ }^{5}$ В то же время названная диспозиция нормы состава ст. 199 УК РФ не отграничила законные от незаконных способов налоговой оптимизации. Чёткой позиции по этому вопросу не даёт и Пленум Верховного суда РФ.

В вышеупомянутом нами постановлении Пленума Верховного суда РФ п. 3 содержится указание на момент окончания налоговых преступлений (ст. ст. 198, 199 УК РФ) - фактическую неуплату налогов (сборов) в срок, установленный налоговым законодательством. Однако всё это не говорит о единообразном представлении и о моменте окончания этого преступления авторами, и в действительности, если мы обратимся к норме ст. 199 УК РФ, то указание - «совершенное в крупном размере» говорит скорее о характеристике деяния, а не о его последствии ${ }^{6}$.

Представляется более точным, указание в диспозиции ст. 199 УК РФ, вместо «совершенное, в крупном или особо крупном размере» на более устойчивое в этом случае - «причинившее крупный ущерб», либо «причинившее ущерб в крупном размере».

В примечании 1 к ст. 199 УК РФ определен конструктивный признак данного состава преступления, о котором мы упоминали выше - «крупный размер», который,

\footnotetext{
5 Клепицкий И.А. Система хозяйственных преступлений. М.: Статут, 2005. С. 456.

6 Данной позиции так же придерживаются И.И. Кучеров, А.Э. Жалинский, И.Н. Соловьёв и др. См. напр.: Кучеров И.И. Преступления в сфере налогообложения. С. 45 ; Соловьёв И.Н. Налоговые преступления в торговле: комментарий к проверкам и уголовным делам. M., 2001. C. 29.
} 
как нам представляется, является довольно сложным для восприятия и его определения. Примеры этому неединичные ошибки в следственной и судебной практике.

Так, 11 апреля 2011 г. Головинский районный суд г. Москвы осудил М. по ч. 1 ст. 199 УК РФ к наказанию в виде штрафа в размере ста тысяч рублей в доход государства. На основании п. «а» ч. 1 ст. 78 УК РФ и ч. 8 ст. 302 УПК РФ М. освобожден от наказания в связи с истечением срока давности уголовного преследования. Судом было установлено, что М. уклонился от уплаты в бюджет налога на прибыль организации и налога на добавленную стоимость на общую сумму свыше 10000000 рублей (81\% от сумм налогов, подлежащих уплате в бюджет, т. е. более $20 \%$ ). Кассационным определением судебной коллегии по уголовным делам Московского городского суда от 1 июня 2011 г. приговор был отменен, уголовное дело направлено на новое судебное разбирательство. В обосновании этого решения указано, что вывод суда об отсутствии в действиях М. квалифицирующего признака п. «б» ч. 2 ст. 199 УК РФ - уклонение от уплаты налога в особо крупном размере, противоречит обвинению, по которому он признан виновным. Исключая указанный квалифицирующий признак из обвинения М., суд первой инстанции сослался на примечание к ст. 199 УК РФ, указав, что сумма неуплаченных налогов в бюджет РФ не превышает 30000000 рублей, поэтому не образует особо крупного размера. Между тем, по смыслу закона (примечания к ст. 199 УК РФ), особо крупным размером признается сумма, составляющая за период в пределах трех финансовых лет подряд более десяти миллионов рублей, при условии, что доля неуплаченных налогов и (или) сборов превышает 20 процентов подлежащих уплате сумм налогов и (или) сборов, либо превышающая тридцать миллионов рублей. Таким образом, установив, что М. уклонился от уплаты в бюджет налога на прибыль организации и налога на добавленную стоимость за период с 01.01.2007 г. по 31.12.2008 г. в общей сумме 17159708 руб. (7 280528 руб. + 9879180 руб.), что составляет $81 \%$ от сумм налогов, подлежащих уплате в бюджет, т.е. более $20 \%$. Таким образом, выводы суда об отсутствии в действиях М. состава преступления, предусмотренного п. «б» ч. 2 ст. 199 УК РФ, являются противоречивыми7.

Уголовный закон должен быть четким и понятным, а его положения просты для понимания каждого. Поэтому установление в примечании статьи фиксированного минимального критерия уклонения, отразится как на практике его правоприменения, так и в общем представлении граждан только с положительной стороны.

В примечании 2 к ст. 199 УК РФ закреплена обязанность правоприменителя, освободить от уголовной ответственности лицо, впервые совершившее это преступление, в случаях полной уплаты этим лицом суммы недоимки и соответствующих пеней, а также суммы штрафа в размере, определяемом Налоговым Кодексом РФ (далее по тексту НК РФ). Обращаясь к относительно новой ст. 76.1 УК РФ, мы можем заметить закрепленное в ч. 1 данной статьи положение, которое гласит: «лицо, впервые совершившее преступление, предусмотренное статьями 198-199.1 УК РФ, освобождается от уголовной ответственности, если ущерб, причиненный бюджетной системе РФ в результате преступления, возмещен в полном объёме».

\footnotetext{
См.: Определение Московского городского суда от 01.06.2011 г. по делу № 22-7511-2011// СПС Консультант Плюс.
} 
Дублирование нормы об освобождении от уголовной ответственности за данное деяние, не отвечает принципам экономии законодательного материала и заставляет задуматься, какая норма из двух подлежит применению при данных обстоятельствах. Исходя из приоритета положений статей Общей части Уголовного кодекса, представляется, что применению подлежит именно ст. 76.1 УК РФ. Упразднение же ч. 2 примечания к ст. 199 УК РФ полностью бы разрешило этот вопрос.

Одним из проблемных вопросов, которые затрагивал в последнее время Президент России, остаётся плохая собираемость налогов в РФ. Как отметил В.В. Путин: «ст. ст. 198-199 УК РФ практически перестали работать». Нам представляется, что причин этому много, и нельзя всё сводить к недостаткам уголовно-правовой охраны. Здесь существуют и иные причины.

Однако если говорить о уголовно-правовых пробелах, то преступления, предусмотренные ч. 1 ст. 198 и ч. 1 ст. 199 УК РФ, а так же ч. 2 ст. 198, относятся к категориям небольшой тяжести. В соответствии с п. «а» ч. 1 ст. 78 УК РФ лицо освобождается от уголовной ответственности, если со дня совершения преступления небольшой тяжести истекли два года. В ст. 113 НК РФ, указано: «лицо не может быть привлечено к ответственности за совершение налогового правонарушения, если со дня его совершения либо со следующего дня после окончания налогового периода, в течение которого было совершено это правонарушение, и до момента вынесения решения о привлечении к ответственности истекли три года». Несоответствие сроков привлечения к юридической ответственности в НК РФ и УК РФ приводит к тому, что большинство уголовных дел подлежат прекращению на различных стадиях уголовного судопроизводства в связи с истечением соответствующих сроков. Расследование преступных схем об уклонении от уплаты налогов и (или) сборов - довольно объёмный процесс, требующий увеличенных сроков давности.

Несомненно, пути разрешения данной проблемы мы видим и в предложениях Президента РФ об увеличении сроков давности по налоговым преступлениям. Однако следует также привести в соответствие и налоговое законодательство, в целях единообразного представления о сроках давности преступлений и налоговых правонарушений.

В заключение, хотелось бы отметить, что для эффективности правового регулирования противодействия налоговым преступлениям, следует четко определить взаимодействие бланкетных норм о налоговых преступлениях с гражданским и налоговым законодательством, поскольку только четкие и отрегулированные механизмы применения этих норм могут привести к должной результативности.

\section{Библиография:}

1. Налоговый кодекс Российской Федерации. Часть первая. Федеральный закон от 31.07.1998 № 146-Ф3 (ред. от 03.12.2013) // СПС Консультант плюс.

\footnotetext{
8 См.: Путин: либерализация налоговой сферы ведет к корректировке УК. Интернет ресурс. URL: http://ria. ru/society/20131114/976922978.html (последняя дата обращения 06.12.2013).
} 
2. Уголовный кодекс Российской Федерации. Федеральный закон от 13.06.1996 № 63-Ф3 (ред. от 25.11.2013) // СПС Консультант плюс.

3. Постановление Пленума Верховного Суда РФ от 28.12.2006 г. № 64 «0 практике применения судами уголовного законодательства об ответственности за налоговые преступления» // СПС Консультант плюс.

4. Волженкин Б.В. Преступления в сфере экономической деятельности по уголовному праву России. СПб.: Юридический центр Пресс, 2007.

5. Клепицкий И.А. Система хозяйственных преступлений. М.: Статут, 2005.

6. Кузнецов А.П. Политика государства в налоговой сфере: уголовно-правовые средства и организационно-тактические методы. Н. Новгород., 1995.

7. Кучеров И.И. Преступления в сфере налогообложения: научно-практический комментарий к УК РФ. М., 1999.

8. Кучеров И.И. Налоговая преступность: криминологические и уголовно-правовые проблемы. дисс... докт. юрид. наук. М., 1999.

9. Путин В.В. либерализация налоговой сферы ведет к корректировке УК. Интернет реcypc. URL: http://ria.ru/society/20131114/976922978.html (последняя дата обращения 06.12.2013).

10. Соловьёв О.Г. Техника законодательной регламентации уголовной ответственности за уклонение от уплаты налогов и таможенных платежей: Монография. М.: Юрлитинформ, 2010.

11. Соловьёв И.Н. Налоговые преступления в торговле: комментарий к проверкам и уголовным делам. М., 2001.

12. Сорокин С.В. Уклонение от уплаты налогов по проекту Уголовного кодекса // Вопросы уголовной ответственности и её дифференциации (в проекте особенной части Уголовного кодекса): сборник научных статей и тезисов. М., 2000.

13. Определение Московского городского суда от 01.06.2011 г. по делу № 22-7511-2011 // СПС Консультант Плюс.

14. Кинсбурская В.А. Ответственность налогоплательщика за непредставление налоговой декларации: спорные вопросы правоприменительной практики // NB: Финансовое право и управление. - 2013. - 1. - C. 17-48. DOI: 10.7256/2306-4234.2013.1.558. URL: http://www.e-notabene.ru/flc/article_558.html

15. Аринин Е.А. Теоретические аспекты организационно-правового механизма налогообложения в Российской Федерации. // NB: Финансовое право и управление. - 2013. 4. - C. 1-29. DOI: 10.7256/2306-4234.2013.4.855. URL: http://www.e-notabene.ru/flc/ article_855.html

\section{References:}

1. Nalogovyi kodeks Rossiiskoi Federatsii. Chast' pervaya. Federal'nyi zakon ot 31.07.1998 № 146-FZ (red. ot 03.12.2013) // SPS Konsul'tant plyus.

2. Ugolovnyi kodeks Rossiiskoi Federatsii. Federal'nyi zakon ot 13.06.1996 № 63-FZ (red. ot 25.11.2013) // SPS Konsul'tant plyus. 
3. Postanovlenie Plenuma Verkhovnogo Suda RF ot 28.12.2006 g. № 64 «0 praktike primeneniya sudami ugolovnogo zakonodatel'stva ob otvetstvennosti za nalogovye prestupleniya» // SPS Konsul'tant plyus.

4. Volzhenkin B.V. Prestupleniya v sfere ekonomicheskoi deyatel'nosti po ugolovnomu pravu Rossii. SPb.: Yuridicheskii tsentr Press, 2007.

5. Klepitskii I.A. Sistema khozyaistvennykh prestuplenii. M.: Statut, 2005.

6. Kuznetsov A.P. Politika gosudarstva $v$ nalogovoi sfere: ugolovno-pravovye sredstva $\mathrm{i}$ organizatsionno-takticheskie metody. N. Novgorod., 1995.

7. Kucherov I.I. Prestupleniya v sfere nalogooblozheniya: nauchno-prakticheskii kommentarii k UK RF. M., 1999.

8. Kucherov I.I. Nalogovaya prestupnost': kriminologicheskie i ugolovno-pravovye problemy. diss... dokt. yurid. nauk. M., 1999.

9. Putin V.V. liberalizatsiya nalogovoi sfery vedet $\mathrm{k}$ korrektirovke UK. Internet resurs. URL: http://ria.ru/society/20131114/976922978.html (poslednyaya data obrashcheniya 06.12.2013).

10. Solov'ev O.G. Tekhnika zakonodatel'noi reglamentatsii ugolovnoi otvetstvennosti za uklonenie ot uplaty nalogov i tamozhennykh platezhei: Monografiya. M.: Yurlitinform, 2010.

11. Solov'ev I.N. Nalogovye prestupleniya $\mathrm{v}$ torgovle: kommentarii k proverkam i ugolovnym delam. M., 2001.

12. Sorokin S.V. Uklonenie ot uplaty nalogov po proektu Ugolovnogo kodeksa // Voprosy ugolovnoi otvetstvennosti i ee differentsiatsii ( $\mathrm{v}$ proekte osobennoi chasti Ugolovnogo kodeksa): sbornik nauchnykh statei i tezisov. M., 2000.

13. Opredelenie Moskovskogo gorodskogo suda ot 01.06.2011 g. po delu № 22-7511-2011 // SPS Konsul'tant Plyus.

14. Kinsburskaya V.A. Otvetstvennost' nalogoplatel'shchika za nepredstavlenie nalogovoi deklaratsii: spornye voprosy pravoprimenitel'noi praktiki // NB: Finansovoe pravo i upravlenie. - 2013. - 1. - C. 17-48. DOI: 10.7256/2306-4234.2013.1.558. URL: http:// www.e-notabene.ru/flc/article_558.html

15. Arinin E.A. Teoreticheskie aspekty organizatsionno-pravovogo mekhanizma nalogooblozheniya v Rossiiskoi Federatsii. // NB: Finansovoe pravo i upravlenie. - 2013. 4. - C. 1-29. DOI: 10.7256/2306-4234.2013.4.855. URL: http://www.e-notabene.ru/flc/ article_855.html 